\title{
La responsabilidad de los administradores societarios en los casos de actuación plural en el derecho argentino*
}

\author{
The Liability of Directors and Officers in Cases of Plural Acting \\ under Argentine Law \\ A responsabilidade dos administradores societários nos casos \\ de atuação plural no direito argentino
}

\author{
MARTíN E. ABDALA** \\ Consejo Nacional de Investigaciones Científicas y Técnicas (Conicet)
}

FECHA DE RECEPCIÓN: 5 dE FEBRERO DE 2014 • FECHA DE ACEPTACIÓN: 25 DE ABRIL DE 2014

Doi: dx.doi.org/10.12804/esj16.02.2014.08

Para citar este artículo: Abdala, M. E. (2014). La responsabilidad de los administradores societarios en los casos de actuación plural en el derecho argentino. Estudios Socio-Jurídicos, 16(2), 243-264. Doi: dx.doi.org/10.12804/esj 16.02.2014.08

\section{RESUMEN}

El tema de la responsabilidad de los administradores societarios es complejo y gana complejidad cuando un hecho dañoso es sindicado a más de un manager. La imputación plural de responsabilidad puede derivar de que los administradores integren un órgano plural colegiado, de que formen un órgano plural no colegiado y de que existió una delegación de funciones. Cuando los administradores integran un órgano plural colegiado, todos ellos serán solidariamente responsables por los daños que provoquen sus determinaciones. Si los managers forman un órgano plural no colegiado, la responsabilidad de cada uno dependerá de la participación personal que tuvo en el hecho dañoso. Finalmente, cuando haya delegación de funciones, habrá que distinguir entre la delegación ordinaria de tareas, supuesto en el que, en principio, responderán solidariamente el administrador delegante y el delegado, y la delegación por asignación específica de funciones, en cuyo caso la imputación se hará atendiendo a la actuación individual de cada uno de los managers.

Palabras clave: sociedades, responsabilidad, administradores, pluralidad, delegación, exoneración.

* Este artículo es resultado del proyecto de investigación titulado "La responsabilidad de los administradores societarios", actualmente en curso, financiado por el Consejo Nacional de Investigaciones Científicas de la República Argentina y en el cual el autor participó en calidad de investigador.

** Doctor en Derecho por la Universidad de Colonia (Alemania). Investigador del Consejo Nacional de Investigaciones Científicas (Argentina); profesor de Derecho Comercial de la Universidad Nacional de Tucumán (Argentina).Correo electrónico: martinabdala@arnet.com.ar 


\section{ABSTRACT}

The issue of directors' and officers' liability is complex, and gains complexity when the harmful act is performed by more than one manager. The plural attribution of liability can result: because managers form a plural organ where its members act together; they form a plural organ where its members act individually; the plural behavior derived from a delegation of tasks. When directors and officers form a plural organ where its members act together, all of them shall be liable for the damage they cause. When they form a plural organ where its members act individual, liability of each will depend on the participation in the harmful event. Finally if the plural behavior derived from a delegation of tasks must be distinguished: when there was a regular delegation of tasks, there is liability of both managers: delegator and delegate; and when there is a specific function assignment, liability depends on the individual performance of each.

Key words: corporations, liability, directors and officers, plurality, delegation, exoneration.

\section{RESUMO}

O tema da responsabilidade dos administradores societários é complexo, e ganha complexidade quando um fato nocivo é sindicado a mais de um manager. A imputação plural de responsabilidade pode derivar de que os administradores integrem um órgão plural colegiado, de que conformem um órgão plural não colegiado e de que existiu una delegação de funções. Quando os administradores integram um órgão plural colegiado, todos eles serão solidariamente responsáveis pelos danos que provoquem suas determinações. Se os managers formam um órgão plural não colegiado, a responsabilidade de cada um dependerá da participação pessoal que teve no fato nocivo. Finalmente, quando tenha delegação de funções será necessário distinguir entre a delegação ordinária de tarefas, suposto no que, em princípio, responderá solidariamente o administrador delegante e o delegado, e a delegação por designação específica de funções, em cujo caso a imputação será feita atendendo à atuação individual de cada um dos managers.

Palavras-chave: Sociedades, responsabilidade, administradores, pluralidade, delegação, exoneração. 


\section{Introducción}

En el dinámico movimiento que tiene la actividad empresarial, se observa con suma frecuencia que las tareas de conducción de las sociedades son ejercidas - a veces de manera concurrente, a veces de forma colegiada y también de modo individual o indistinto- por diversas personas, como, por ejemplo, directores, gerentes, apoderados, administradores, etc.

En ciertos casos, ello ocurre porque algunos tipos societarios permiten confiar las funciones de administración de las sociedades a órganos plurales, como, por ejemplo, el directorio en las sociedades anónimas, la gerencia múltiple en las sociedades de responsabilidad limitada, etc. En otros supuestos, ello obedece a que la complejidad o el volumen de las tareas de gestión empresaria obligan a que estas sean realizadas por diferentes managers de la sociedad.

En todos estos casos en los que actúan una pluralidad de administradores societarios, cuando alguna de las decisiones que ellos toman o los actos que ellos realizan provocan un daño, la imputación de responsabilidad sumará un ingrediente de complejidad, pues el deber resarcitorio podrá sindicarse a más de un manager, es decir, se tratará de una imputación plural.

En los acápites siguientes, analizaremos entonces los problemas que se presentan en aquellos casos en los que un hecho dañoso es sindicado a más de un administrador societario, distinguiendo entre los supuestos en los que la sindicación plural obedece a que los managers forman un órgano plural colegiado; los casos en los que ellos integran un órgano plural no colegiado; y, finalmente, los supuestos en los que la pluralidad obedece a que existió una delegación de funciones.

\section{Responsabilidad en los órganos colegiados}

Como referimos en los párrafos anteriores, un primer supuesto en el que puede reclamarse el resarcimiento de un hecho dañoso a varios administradores se presenta cuando se concreta una imputación de responsabilidad por pertenencia a un órgano plural societario.

La forma en que se concretará la sindicación de responsabilidad en estos supuestos depende de un factor determinante: si el mentado órgano 
plural es colegiado o no lo es. En el primer caso, es decir, cuando el órgano plural es colegiado, todos sus miembros serán solidariamente responsables por los daños que provoquen sus determinaciones, comportamientos y omisiones. En el segundo caso, como veremos en el acápite siguiente, la responsabilidad dependerá de la actuación individual de cada uno de los administradores.

Así las cosas, a poco de andar advertimos que la sola pertenencia a un órgano colegiado societario puede significar que todos sus miembros deban responder, en forma solidaria, ante una imputación de responsabilidad derivada de una determinación adoptada por ese cuerpo plural. ${ }^{1}$

\subsection{Fundamento de la responsabilidad}

La decisión del legislador de consagrar esta responsabilidad solidaria de los miembros de los órganos colegiados por su sola pertenencia a estos no es caprichosa y se justifica porque el hecho de integrar un cuerpo plural de esas características, en el que la voluntad del órgano es la resultante de la coincidencia de la mayor parte de las voluntades individuales que lo forman, amerita que todos sus miembros estén ligados por una misma responsabilidad (Gagliardo, 2004).

Los integrantes del órgano plural que contribuyeron a formar la mayoría necesaria para aprobar la decisión que, a la postre, resulte dañosa y dispare la imputación de responsabilidad quedan por esa razón solidariamente ligados con esa determinación. Quienes en cambio forman la minoría también tendrán responsabilidad solidaria, a menos que demuestren una causa de exoneración (que analizamos más abajo), por no haber ejercido adecuadamente las atribuciones recíprocas de control sobre las actividades de sus pares y de contralor sobre los actos de gestión administrativa

1 La jurisprudencia resolvió al respecto que la responsabilidad del directorio de una sociedad anónima nace de la sola circunstancia de integrar el órgano de gobierno, de manera que cualesquiera sean las funciones que efectivamente cumpla un director su conducta debe ser calificada en función de la actividad obrada por el órgano, aun cuando el sujeto no haya actuado directamente en los hechos que motivan el encuadramiento. Cf. Cámara Nacional Comercial, Sala B, in re Only Plastic S.A. S/Quiebra, S/Incidente de calificación de conducta, sentencia del 26 de marzo de 1991, y, en igual sentido, in re Eugenio Izak S.A. S/Quiebra, S/Incidente de calificación de conducta, sentencia del 7 de diciembre de 1994, e in re Marsicano, Oscar c. San Sebastián Sacif y otros, sentencia del 28 de abril de 2009 . 
de la sociedad, al no haberse opuesto formalmente a lo decidido por el órgano, haciendo uso de los resortes jurídicos con los que cuenta para esos efectos.

Pero, además de estas razones dogmáticas, existe también una justificación de naturaleza práctica para la consagración de esta responsabilidad solitaria de los administradores societarios que integran los órganos colegiados: sería sumamente complejo, cuando no imposible -tanto para la sociedad como para los socios-, lograr el resarcimiento de los daños sufridos por las irregularidades en las decisiones de los órganos plurales, si primero tuviera que determinarse cuál o cuáles de sus integrantes son los realmente responsables y cuáles no (Sasot Betes y Sasot, 1980).

\subsection{El factor de imputación al que puede recurrirse}

Ahora bien, recordemos que, en materia de responsabilidad de los administradores societarios, el principio imperante es que el factor al que debe recurrirse para concretar la imputación es el subjetivo, en virtud de lo cual la existencia del deber resarcitorio presupone que el manager haya actuado con culpa o dolo. ${ }^{2}$

Pero hete aquí que, en los casos de imputación de responsabilidad por la sola pertenencia a un órgano plural colegiado, es complejo explicar cómo puede afirmarse la existencia de un factor subjetivo de imputación, sin que haya mediado una actuación personal y directa de todos los administradores que integran el órgano, a quienes se les pretenda sindicar la obligación resarcitoria.

En una primera aproximación, podría pensarse que, en estos casos, la imputación de responsabilidad es objetiva, pues se concreta la sindicación del deber resarcitorio sin que haya existido una actuación con culpa o dolo del administrador societario. ${ }^{3}$

2 Doctrina de los artículos 59, 274 y concordantes de la Ley de Sociedades Comerciales y artículo 1109 del Código Civil.

3 De todos modos, no debemos ni por un momento olvidar que la moderna doctrina civilista afirma que incluso la responsabilidad objetiva tiene elementos propios de la imputación subjetiva, pues presupone una elevada o refinada conciencia de diligencia (verfeinerte Verantwortungsbewußtsein) que, por ello, impone el deber reparatorio aun en aquellos casos en los que, a pesar del actuar irreprochable, el daño no pudo ser evitado. Cf. Kötz (1996). 
Sin embargo, sin siquiera realizar mayores esfuerzos, advertimos que esa afirmación no sería correcta, pues -como ya lo adelantamos- la Ley de Sociedades Comerciales prevé una responsabilidad in comitendo para los administradores que personalmente causen el daño y una responsabilidad in vigilando para los restantes managers (Otaegui, 1979).

En ese orden de ideas, cuando se concreta una imputación fundada en la sola pertenencia a un órgano plural colegiado, la sindicación de responsabilidad sigue siendo subjetiva y se justifica en la denominada culpa in vigilando, pues el solo hecho de integrar un órgano societario plural colegiado obliga a todos sus miembros a un estrecho y estricto control recíproco, cuyo soslayo conducirá a la sindicación del deber resarcitorio. ${ }^{4}$

Así las cosas, aun cuando ni el estatuto, ni las convenciones particulares que se celebren al incorporar a un administrador societario, ni la propia Ley de Sociedades Comerciales lo indique expresamente, es función de todos los integrantes de un órgano plural colegiado societario controlar la gestión de los restantes miembros de este. ${ }^{5}$

Por esa razón, el mal desempeño de la función por un administrador societario no solo puede verse configurado por la participación directa en hechos o actos violatorios de la ley o los estatutos, sino también en la omisión de realizar las diligencias necesarias que exijan las circunstancias de tiempo, lugar y modo, para evitar o frustrar el incorrecto proceder de otros administradores que integran el órgano colegiado. ${ }^{6}$

4 La jurisprudencia sostuvo, por ejemplo, que el director de una sociedad anónima no puede pretender eximirse de responsabilidad arguyendo que el presidente del directorio absorbió la conducción de la empresa con exclusión de los demás, puesto que la conducta omisiva de un director, derivada de la ignorancia, imprevisión, negligencia, impericia o imprudencia, revela su falta de aptitud para el cargo y no lo excusa de su responsabilidad, ya que los administradores de una sociedad que omiten ejercer sus funciones en la gestión social incurren en culpa in vigilando. Cámara Nacional Comercial, Sala B, in re Jinkus, Gabriel A. c. Video Producciones Internacionales S.A. y otros, 1997. Véase al respecto, Perciavalle (2007).

5 Cf. Cámara Nacional Comercial, Sala A, in re Vid y Com. Video y Comunicaciones S.A. S/Quiebra, S/Incidente de calificación de conducta, sentencia del 10 de julio de 1992, y Sala B, in re Viajes Guinea S.A. S/Quiebra S/Incidente de calificación de conducta, sentencia del 11 de marzo de 1993; in re Taverniti S.A. S/Quiebra S/Incidente de calificación de conducta, sentencia del 28 de abril de 1995, y Sala E, Inmobiliaria Alonso S/Incidente de calificación de conducta, sentencia del 27 de mayo de 1994.

6 Cf. Cámara Nacional Comercial, Sala A, in re Eledar S.A. c. Serer, Jorge S/Sumario, sentencia del 8 de octubre de 1997. 


\subsection{La exoneración de responsabilidad}

Ahora bien, el principio al tenor del cual todos los administradores societarios que integran un órgano plural colegiado son solidariamente responsables por los perjuicios que produzca las decisiones de este, reconoce algunas excepciones.

La cuestión es abordada por el artículo 274 de la Ley de Sociedades Comerciales, que es una de las pocas normas de nuestro ordenamiento jurídico societario que habla de la responsabilidad de los administradores y que, como referimos en otro trabajo de nuestra autoría (Abdala, 2010), tiene como única virtud el corroborar las conclusiones de la doctrina y de la jurisprudencia vernácula en cuanto a que, para concretar sindicaciones de responsabilidad de los managers, debe recurrirse a los factores subjetivos de atribución, esto es, al dolo y la culpa. Pero se trata, sin embargo, de una virtud nimia, por un lado, porque las normas jurídicas no tienen como finalidad u objetivo aclarar cuestiones, tarea que, en realidad, corresponde a la doctrina, $y$, por otro lado, por cuanto -en rigor de verdad- en este caso concreto, aun sin esa aclaración y con la sola aplicación de los principios de la teoría general de la responsabilidad civil, se llega a idéntica conclusión. ${ }^{7}$

La norma que analizamos establece en su primer párrafo que los directores de las sociedades anónimas responden solidariamente por el mal desempeño de su cargo y luego, en el tercer párrafo, ${ }^{8}$ refiere a la problemática que sopesamos y prevé una categórica exención de responsabilidad, al establecer que no se concretará una imputación del deber reparatorio a los directores de las sociedades anónimas que se hubieran opuesto, del

7 Los defectos que tiene el mentado artículo 274 de la Ley de Sociedades Comerciales son, en cambio, mucho más importantes que la mencionada bondad. El menor de ellos (que, ante la importancia del mayor, se empalidece y se convierte en anecdótico) es que precisa que los directores "responden ilimitada y solidariamente", utilizando de esa manera una expresión impropia, que se presta a profundas confusiones. Con suma frecuencia, observamos, tanto en la doctrina como en la jurisprudencia, la utilización, como una suerte de muletilla, de la expresión "responsabilidad solidaria e ilimitada", la cual no solo es sobreabundante, sino que incluso es impropia, pues es obvio que nuestro ordenamiento jurídico no prevé limitaciones de la responsabilidad. El defecto mayor es mucho más grave: el uso de la expresión "culpa grave" arroja un grueso manto de oscuridad y confusión, que termina por otorgarle imprecisión al sistema. Cf. Abdala (2010).

8 A las disposiciones contenidas en el segundo párrafo del artículo 274 de la Ley de Sociedades Comerciales nos referimos, por una cuestión de adecuada sistematización, más abajo, en el acápite siguiente. 
modo en que lo analizamos en los acápites siguientes, a la resolución que resulte a la postre dañosa.

Esta excepción fue incorporada por la Ley 22.903 y, si bien no es aplicable por analogía a todos los administradores societarios ni a todos los tipos de sociedades, ${ }^{9}$ ofrece un categórico criterio interpretativo para justificar exoneraciones de responsabilidad por falta de participación del manager en la formación de voluntad del órgano colegiado.

Así las cosas, advertimos entonces que, contrario a lo que podría pensarse en un primer análisis de la problemática que sopesamos, el grado de participación de cada administrador en el momento en que se forma la voluntad del órgano plural tiene una relevancia significativa y será determinante para precisar el nivel de responsabilidad de cada manager, hasta el punto tal que puede incluso justificar una exoneración del deber resarcitorio.

Sin embargo, esta eximición no altera en esencia el régimen de responsabilidad de los directores, sino que introduce una posibilidad de apreciación para asignarla o graduarla si se dan ciertas circunstancias (Zaldívar, 1983), y corrobora que, en los casos en los que se sindica el deber resarcitorio a los managers por su pertenencia a los órganos plurales, el factor de imputación al que se recurre es, como referimos, subjetivo.

\subsection{Participación en la toma de la decisión}

En ese orden de ideas, para sopesar el grado de responsabilidad que le cabe a un administrador societario por formar parte de un órgano social colegiado que toma una decisión que desencadene una imputación del deber resarcitorio, será necesario comenzar preguntándonos si el manager participó o no de la reunión en la que se deliberó y se tomó esa determinación.

La expresión 'reunión' en este caso no refiere únicamente al encuentro físico de los diferentes integrantes del órgano plural, que sería el supuesto más común y ortodoxo en la toma de decisiones de una sociedad, sino que incluye también los acuerdos que realizan los integrantes de un órganos plural colegiado, aun sin haber confluido en un determinado momento a un mismo espacio físico, recurriendo para ello, por ejemplo, a cualquier

9 Ello por cuanto no puede recurrirse a la analogía para justificar exenciones de responsabilidad. 
tipo de elementos que le permitan aunar voluntades sin la necesidad de una aproximación física.

Así las cosas, si el administrador societario hubiera participado de esa reunión hay que distinguir si votó a favor de la resolución que luego genera la imputación de responsabilidad, si se abstuvo o si votó en contra de ella.

En el primer supuesto, es decir, cuando el director vota a favor de la resolución que dispare la imputación del deber resarcitorio, obviamente no habrá razones para una exoneración de responsabilidad, pues todos los miembros del órgano plural colegiado que votaron favorablemente la resolución contribuyeron, de esa manera, a formar la voluntad del órgano colegiado y son entonces autores de ella, debiendo en consecuencia responder en el resarcimiento de los daños que esta pudiera provocar.

El segundo caso por analizar se presenta cuando un integrante del órgano plural colegiado se abstiene en la votación. Esa abstención es insuficiente para eximir al director de responsabilidad, por cuanto la exoneración del deber reparatorio es una ventaja excepcional, una morigeración al régimen general de responsabilidad, $y$, en consecuencia con ello, nuestro ordenamiento jurídico exige posturas categóricas para obtener ese beneficio. Por otro lado, nuestro ordenamiento societario impone a los administradores societarios la tarea de controlar el comportamiento de los demás integrantes de los órganos plurales colegiados, lo que les exige la concreción de conductas activas y diligentes, razón por la cual la sola abstención o la ausencia en deliberación no son suficientes para eximirles de responsabilidad.

Finalmente, el tercer supuesto que puede presentarse es cuando el administrador societario vota en contra de la resolución que provoca la sindicación del deber resarcitorio. En este caso, es posible que el mentado manager obtenga el beneficio de la eximición de responsabilidad, siempre y cuando formalice la protesta, en la forma y del modo en que explicamos en el siguiente acápite.

Ahora bien, la cuestión cambia radicalmente cuando el director no participó de la reunión o del encuentro en el que se adoptó la decisión que desencadena la imputación de responsabilidad. En este supuesto, habrá que distinguir los casos en los cuales el administrador societario estaba anoticiado de la reunión de aquellos supuestos en los que no lo estaba, $\mathrm{y}$, entre estos últimos, diferenciar si el manager justificó o no su ausencia. 
Si el administrador societario no estaba anoticiado de la reunión del órgano plural colegiado que integra ${ }^{10} \mathrm{o}$ si, estándolo, no concurrió por un motivo justificado, podrá eximirse de la responsabilidad que pudieran desencadenar las decisiones que se tomen en esa reunión, siempre y cuando, luego de tomar conocimiento de lo decidido en ella, hubiera formalizado la protesta del modo en que se explica en el acápite siguiente.

Cuando en cambio el administrador hubiera estado notificado de la reunión del órgano plural colegiado y no concurriera injustificadamente, no será posible eximirle de responsabilidad por las decisiones que tome el órgano plural en esa reunión, cuya imputación se justificará plenamente por haber omitido el manager ejercer las funciones de contralor inherentes a su cargo.

Ahora bien, muchas veces los órganos plurales colegiados toman decisiones en reuniones impropias o irregulares en las cuales no se concretan votaciones formales, observando los modos y procedimientos previstos por el ordenamiento jurídico. En estos supuestos en los que no se realiza una votación propia, e igualmente se ejecuta la determinación que luego resulta dañosa, el administrador societario podrá obtener el beneficio de la exoneración de responsabilidad si demuestra que, efectivamente, la decisión que desencadena la imputación del deber resarcitorio no fue orgánicamente adoptada por el órgano plural que él integra, sino que fue ejecutada por sus integrantes sin observar y respetar las formalidades intrasocietarias previstas para adoptar esas decisiones.

Para ello, deberá, claro está, demostrar que activó y movilizó los resortes societarios correspondientes para juzgar a los restantes administradores que violaron el sistema de toma de decisiones del órgano plural colegiado y, además, que tomó todas las medidas necesarias para enervar la ejecución de la decisión impropia y para reducir o eliminar sus consecuencias.

Del mismo modo, tampoco podrá concretarse una imputación de responsabilidad solidaria a todos los integrantes de un órgano plural $\mathrm{co}^{-}$ legiado cuando uno de sus miembros actuare sin mediar acuerdo con el órgano, y no fuera una decisión propia de la gestión cotidiana de negocios (Nissen, 2006).

10 En estos casos, claro está, habrá también que evaluar el agravamiento de la responsabilidad de los demás integrantes del órgano plural por la vulneración del sistema de toma de decisiones intrasocietarias. 
En estos supuestos en los que se viola el régimen de representación plural, no solo no podrá imputarse el deber resarcitorio a los integrantes del órgano plural colegiado, sino que tampoco podrá sindicarse el acto a la sociedad, debiendo responder por ello únicamente los managers actuantes, excepto -claro está- cuando la responsabilidad deriva de la realización de un acto que viola el régimen de representación plural, pero implica contraer una obligación mediante títulos valores, por contratos entre ausentes, de adhesión o concluidos mediante formularios, ${ }^{11}$ pues en ese caso el acto se imputa igualmente a la sociedad, a quien podrá responsabilizársela, sin perjuicio de que luego esta podrá reclamar la restitución de la indemnización al administrador que actuó violando el régimen de representación plural.

La excepción a este principio es casi evidente: en aquellos casos en los que el tercero tuviere conocimiento efectivo de que el acto se celebra en infracción de la representación plural, las obligaciones emergentes del negocio jurídico celebrado en esa condiciones no serán exigibles a la sociedad, sino únicamente al administrador actuante.

\subsection{Formalización de una protesta}

Ahora bien, como referimos en los párrafos anteriores, si el administrador votó en contra de la decisión que luego desencadena la imputación de responsabilidad, o bien no participó de la reunión en la que se adoptó esta, porque no fue notificado o a raíz de una ausencia justificada, podrá eximirse de responsabilidad demostrando que formalizó la correspondiente protesta.

Esta protesta debe ser realizada por escrito, es decir, no basta con la verbalización del desacuerdo, pues el ordenamiento jurídico exige expresamente la observancia de esa formalidad, que puede ser satisfecha o cumplida por cualquier medio que permita acreditar que el administrador participó de la reunión y que no estuvo de acuerdo con la resolución adoptada.

La constancia escrita de la protesta del administrador societario puede asentarse en las propias actas de la reunión en la que se tome la decisión que luego resulte dañosa. Es cierto que, en algunos casos, los administradores no pueden imponer su voluntad de dejar acreditada por escrito su oposición, puesto que, cuando se celebran este tipo de reuniones y existe

11 Cf. la doctrina del artículo 58 de la Ley de Sociedades Comerciales. 
desacuerdo entre los grupos que conducen la sociedad, muchas veces los que detentan mayor poder impiden incluso a los disidentes dejar constancia de sus desavenencias, razón por la cual, cuando se producen este tipo de reuniones conflictivas, es recomendable la presencia de un notario para documentar su desarrollo.

Luego de formalizada la protesta por escrito, el administrador debe inmediatamente dar noticia al síndico de la sociedad de que se ha opuesto a una decisión tomada por el órgano plural, por considerar que esta es inconveniente para los intereses de la sociedad. ${ }^{12}$

Esa noticia debe ser efectuada antes de que la responsabilidad del administrador societario se denuncie o se ejerza una acción judicial a esos efectos, pues, luego de que alguna de esas dos alternativas acaezca, ya no podrá el manager disidente beneficiarse con la eximición de responsabilidad..$^{13}$

\section{Responsabilidad en órganos plurales no colegiados}

Ahora bien, cuando el órgano plural societario no es colegiado, verbigracia una gerencia plural indistinta de una sociedad de responsabilidad limitada o de una sociedad anónima, el comité ejecutivo de una sociedad anónima, etc., la cuestión cambia sustancialmente.

En estos casos, si el cuerpo plural toma una determinación que, a la postre, resulte dañosa, el deber resarcitorio no podrá sindicarse en forma solidaria a todos sus miembros, por cuanto en estos supuestos no es necesario que concurran las voluntades individuales de sus integrantes para formar la voluntad del órgano plural, ya que cada manager puede actuar de manera individual e indistinta en representación de la sociedad.

Como consecuencia, a la hora de concretar una imputación de responsabilidad, cada administrador será responsable individualmente de acuerdo con el grado de participación personal que tuvo en el asunto y el juez deberá, en consideración a ello, fijar la parte que a cada uno corresponde en la reparación de los perjuicios.

12 En caso de que la sociedad no tuviera síndico, la noticia debe ser dirigida al órgano de contralor societario, lo cual dependerá del tipo de sociedad de la que se trate.

13 Esa denuncia pueda hacerla cualquier interesado y, como lo establece expresamente el artículo 274 de la Ley de Sociedades Comerciales, puede concretarse ante el directorio, el síndico, la asamblea o la autoridad competente. Véase al respecto, Otaegui (1979). 
Este criterio hermenéutico propuesto es idéntico al previsto por el artículo 157 in fine de la Ley de Sociedades Comerciales, que, si bien refiere únicamente para los gerentes de las sociedades de responsabilidad limitada, por analogía puede aplicarse como un parangón interpretativo a todas las sociedades y a todos los administradores que actúen en órganos plurales no colegiados. ${ }^{14}$

\section{La delegación de funciones}

Finalmente, el tercer supuesto en el cual puede concretarse una imputación de responsabilidad que afecte a varios administradores societarios se presenta en los casos de delegación de tareas.

Recordemos que nuestro ordenamiento jurídico societario consagra el principio de la indelegabilidad de las funciones que ejercen los administradores societarios, al establecer en el artículo 266 de la Ley de Sociedades Comerciales que el cargo de director de una sociedad anónima es personal e indelegable. ${ }^{15}$

Incluso, la doctrina va más allá que la propia norma y refiere que no solo no pueden delegarse las funciones de cada director considerado en forma aislada, sino que tampoco puede hacerse lo propio con las atribuciones del directorio como órgano o cuerpo colegiado (Martorell y Figueroa, 1994).

Esta indelegabilidad se justifica por cuanto los managers son elegidos en función de sus características personales y su idoneidad, razón por la cual el cargo es intuito personae y debe ser ejercido de esa manera.

Por otro lado, no debemos ni por un momento soslayar que, si se pudieran delegar las funciones del administrador societario a un tercero, no solo se vulnerarían esos principios, sino que, y esto es lo más grave,

14 Esa norma distingue los supuestos en los que la gerencia es ejercida en forma colegiada de los casos en los que está en cabeza de una pluralidad de personas, pero ejerciendo la representación de manera individual o, como se estila decir, 'indistinta'. En el primer caso, es decir, cuando la gerencia de la sociedad es colegiada, se aplican las disposiciones relativas a la responsabilidad de los directores de las sociedades anónimas que analizamos a continuación, y, en el segundo, la determinación de responsabilidades de acuerdo con el grado de participación.

15 Esta norma, si bien está prevista para los directores de las sociedades anónimas, puede también por analogía aplicarse a los restantes administradores, tanto de sociedades anónimas como de los demás tipos societarios. 
se desnaturalizaría el régimen de responsabilidad de los administradores societarios previsto por los artículos 59, 274 y concordantes de la Ley de Sociedades Comerciales (Nissen, 2006).

Ahora bien, esa indelegabilidad refiere obviamente solo a la parte funcional u orgánica del ejercicio del cargo de administrador societario, lo cual es fácilmente comprobable si se advierte que el mentado artículo 266 de la Ley de Sociedades Comerciales precisa y aclara que los directores no podrán, en caso de ausencia, votar por correspondencia, integrar el quórum de la reunión o hacer conocer su voto por medio de otro director. ${ }^{16}$

Pero hete aquí que esa indelegabilidad de la parte funcional del cargo no impide, y es una práctica muy frecuente, que los administradores de sociedades deleguen sus tareas ejecutivas ordinarias y extraordinarias en otras personas: gerentes generales, gerentes especiales, apoderados, etc.

El artículo 269 de la Ley de Sociedades Comerciales prevé expresamente que el estatuto de una sociedad anónima puede organizar un comité ejecutivo, integrado por directores, para gestionar los negocios ordinarios de la empresa y el artículo 270 de la misma ley faculta al directorio a designar gerentes generales y especiales del ente y a delegar en ellos funciones ejecutivas de la administración. Además, el órgano colegiado tiene facultades para otorgar poderes especiales o generales, tanto a sus integrantes como a terceros, a fin de que se ocupen de los asuntos de la sociedad.

Ahora bien, en todos estos casos, la pregunta por responder es qué debe hacerse cuando los administradores delegados toman decisiones empresarias o realizan actos que, a la postre, provocan daños resarcibles. Para contestar ese interrogante, tendremos que distinguir dos tipos de delegación de funciones: al primero lo llamaremos delegación ordinaria y al segundo lo denominaremos delegación por asignación específica de funciones.

\subsection{La delegación ordinaria}

En aquellos supuestos en los que hay una delegación ordinaria de funciones, el principio que rige es que ella no excluye la responsabilidad de los administradores delegantes, quienes, a pesar de que en esos casos no

16 Cabe en este punto aclarar que la norma, para facilitar la dinámica societaria, autoriza a delegar el voto en cabeza de otro director, pero únicamente en aquellos casos en los que se hubiera alcanzado el quórum necesario, sin el cómputo del administrador ausente. 
intervienen en forma directa en la ejecución o realización del acto antijurídico que provoca el daño resarcible, deberán responder por lo actuado por los administradores delegados, solidariamente con estos. ${ }^{17}$

Es decir que, cuando la actuación de un administrador delegado provoque un daño resarcible, la imputación de responsabilidad se hará a ese manager delegado y al administrador $\mathrm{u}$ órgano de administración delegante, todos los cuales responderán en forma solidaria, sin perjuicio, claro está, de que el administrador u órgano de administración delegante podrá reclamar al administrador delegado la repetición de las sumas indemnizatorias que tuvieron que afrontarse por hechos antijurídicos que fueron imputables a este último.

En una primera aproximación, podría pensarse que la sindicación de responsabilidad al administrador delegante puede fundarse en el artículo 1113 del Código Civil, que establece que la obligación del que ha causado un daño se extiende a los perjuicios que causaren los que están bajo su dependencia. Se trataría entonces de aplicar las disposiciones de esa norma y las conclusiones que al respecto ha elaborado la doctrina civilista a un caso de responsabilidad societaria, arguyendo que los subordinados o delegados de un administrador societario ocupan una posición idéntica a los dependientes del agente a los que refiere el artículo, pues obviamente ellos son terceros (ya que, desde lo ontológico, son personas distintas a los administradores societarios), y no pertenecen, justamente por la mentada relación de acatamiento, al grupo de terceros por quienes los managers 'no deban responder'.

En apoyo de esa postura, podría también destacarse que existen otras normas que integran nuestro ordenamiento jurídico que refieren a la problemática y otorgan una solución similar, como, por ejemplo, el artículo $9^{\circ}$ de la Ley 11.683, que establece que los obligados y responsables de acuerdo con las disposiciones de esa ley tributaria lo son también por las consecuencias del hecho u omisión de sus factores, agentes o dependientes. ${ }^{18}$

17 Esa solidaridad, que recordemos que en nuestro derecho no se presume y debe derivar de una norma concreta que la establezca, surge en el caso que analizamos de la aplicación del artículo 59 de la Ley de Sociedades Comerciales, que con meridiana claridad establece que los administradores y los representantes de la sociedad que faltaren a sus obligaciones son responsables, ilimitada y solidariamente, por los daños y perjuicios que resultaren de su acción u omisión.

18 En la jurisprudencia, encontramos un sinnúmero de casos en los que los contribuyentes pretenden, con suerte diversa, eximirse de la imputación de responsabilidad arguyendo que el 
Ahora bien, no debemos ni por un momento olvidar que, como referimos, el sistema de responsabilidad de los administradores societarios exige la existencia de un factor subjetivo de imputación, esto es, la culpa o el dolo del manager, y que, incluso en los casos de imputación plural, se satisface ese requerimiento y se sindica responsabilidad con base en la culpa in vigilando.

En ese orden de ideas, resulta inaceptable la propuesta de aplicar el artículo 1113 del Código Civil al caso que analizamos, pues implicaría admitir un proceso de objetivización de la responsabilidad societaria que, en nuestra opinión, no se condice con los principios que gobiernan este régimen.

Incluso más, hasta la aplicación del principio al tenor del cual los administradores delegantes deben, por culpa in vigilando, responder solidariamente con los delegados por todos los actos dañosos que estos realicen debe ser efectuada con suma prudencia, para evitar que conduzca a situaciones sumamente injustas, pues no podemos ni por un momento olvidar que, cuanto más grande sea la estructura de la empresa, más difícil será para los administradores delegantes ejercer un control estricto de los actos y comportamientos de los administradores delegados, y, en muchos casos, resultaría inicuo responsabilizarlos por decisiones cuyo contralor no les fuera razonablemente exigibles.

Tampoco podemos soslayar que, en muchos casos, la conducta del administrador delegado puede tener ciertas características (pensemos, por ejemplo, en maniobras delictuales, comportamientos dolosos, etc.), que, aun con un elevado nivel de exigencia al administrador delegante, no podría reprochársele como una violación de sus obligaciones por culpa in vigilando.

Todo ello nos lleva a concluir que, en muchos casos, es posible eximir de responsabilidad a los administradores societarios delegantes que no tuvieron ni participaron en la gestión inmediata y directa de la actuación de los administradores delegados que provoque la imputación de responsabilidad, ${ }^{19}$

incumplimiento tributario, en realidad, obedeció a una conducta del dependiente. Así, por ejemplo, in re Ghilino, Pablo Gabriel (La Sirena S.A.) s/Apelación, la Sala II de la Cámara Federal de Apelaciones de Bahía Blanca entendió que, aun cuando el empleado de una sociedad anónima no integre la persona jurídica, no es un tercero ajeno a esta, sino que se vincula con ella por la relación de dependencia laboral y obliga a su empleador en los términos del artículo $9^{\circ}$ de la Ley 11.683, y confirmó la sentencia de la instancia anterior que ordenó la sanción de tres días de clausura y multa, impuesta por la AFIP-DGI, por no haber emitido factura, ticket, remito o documento equivalente por una operación de venta a un cliente ocasional.

19 Así lo sostiene, por ejemplo, la Cámara Nacional Comercial, Sala B, sentencia del 15 de marzo de 1982, publicada en El Derecho, t. 99-444. 
siempre y cuando (y esta reserva es en nuestra opinión muy importante) aquellos hubieran agotado los recursos a su alcance para corregirla y hubieran tomado las medidas ulteriores para enervar, reducir o reparar el daño (en contra Nissen, 2006).

\subsection{La delegación por asignación específica de funciones}

La situación es diferente en aquellos supuestos en los que se encomienda a uno o más de un administrador societario (director, gerente, apoderado, etc.) la ejecución de alguna tarea específica o la realización de un encargo determinado y concretamente precisado, es decir, en los casos en los que se realiza una asignación específica de funciones.

En nuestro ordenamiento jurídico societario, esta herramienta está prevista en el segundo párrafo del artículo 274 de la Ley de Sociedades Comerciales, que autoriza a las sociedades anónimas a llevar a cabo asignaciones específicas de funciones y establece que, en esos casos, la imputación de responsabilidad por la actuación del administrador delegado se hará atendiendo a la actuación individual de cada uno de los intervinientes.

Es decir que esta norma permite a los miembros del órgano societario delegante eximirse de la imputación del deber resarcitorio que pudiera corresponderles por su sola pertenencia al órgano plural, en caso de que el administrador delegado a quien se le asignaron funciones específicas realice un acto que a la postre resulte dañoso.

La incorporación por la Ley 22.903 del régimen de imputación de responsabilidad atendiendo a la actuación individual del director no invalida la mentada regla de la responsabilidad solidaria de los integrantes del órgano societario colegiado, sino que concibe, para cuando hubieran asignado funciones en forma personal, una presunción de responsabilidad individual imputable solo al director que asume determinadas tareas.

En otras palabras, la modificación no implica atenuar o atemperar la responsabilidad de los integrantes del órgano de administración, ni desembarazar al directorio por las consecuencias de acciones que sean perjudiciales a la sociedad, sino únicamente dejar en claro que la imputación de responsabilidad se hará atendiendo a esa actuación individual cuando se dan las circunstancias establecidas por la ley (Verón, 1998). 
Ahora bien, la asignación específica de funciones no puede ser discrecionalmente decidida por cualquier órgano de la sociedad (así, por ejemplo, ella no puede ser resuelta por el directorio), sino que debe preverse en el estatuto, en el reglamento interno de funcionamiento societario o bien debe surgir de una decisión asamblearia.

Cabe en este punto aclarar que la Ley de Sociedades Comerciales no contiene una norma general, aplicable a todos los tipos de sociedades, que prevea la posibilidad de recurrir a esta herramienta de asignar a un manager funciones específicas o determinadas, ni contempla -mucho menos- el modo de hacerlo y la forma de resolver los problemas que derivan de su utilización. Por esa razón, entendemos que el mentado artículo solo es aplicable a las sociedades anónimas y, por tratarse de una norma que implica una modificación (y más precisamente una moderación o morigeración) del régimen de responsabilidad de los administradores societarios, no puede aplicarse por analogía a los restantes tipos societarios.

Por otro lado, y siempre según lo dispuesto por el artículo 274 de la Ley de Sociedades Comerciales, es requisito para la aplicación de la norma que la decisión de la asamblea de asignar específicamente funciones y la designación de las personas que las realizarán estén inscriptas en el Registro Público de Comercio. Estas exigencias de publicidad se justifican por cuanto la morigeración del régimen de responsabilidad es aplicable no solamente a aquellos casos en los que se intente la interposición de una acción social, sino también cuando se ensaye una acción individual de responsabilidad, de modo tal que la comunidad tenga la oportunidad de saber que hay ciertas tareas de la sociedad que fueron delegadas a determinados administradores societarios.

Cabe aclarar que esa publicidad registral no prevalece ni puede estar por encima de la propia realidad, de modo tal que la exención de responsabilidad no podrá concretarse en aquellos casos en los que se hubiera cumplimentado esa publicidad pero, en verdad, esta no fuera coincidente con la realidad, porque, por ejemplo, las funciones específicas no son ejercidas por el administrador que aparece en registro público de comercio como encargado de la especial encomienda. ${ }^{20}$

20 En igual dirección, la jurisprudencia resolvió que la publicidad registral del cese de funciones del presidente del directorio de una sociedad anónima y la designación del nuevo titular no tienen 
Por lo demás, el objeto de las tareas delegadas no puede comprender materias que resultan privativas, exclusivas e indelegables del directorio, pues, en estos supuestos y aun cuando se haya dado cumplimiento a los requisitos señalados, los miembros de ese órgano no podrán eximirse de responsabilidad, sino solamente cuando haya efectuado la oposición a la cuestión controvertida, conforme lo analizado anteriormente.

\section{Conclusiones}

1. La imputación de responsabilidad a los administradores societarios suma un importante ingrediente de complejidad cuando se dirige a una pluralidad de managers: esto es, cuando se sindica el deber resarcitorio a los miembros de un órgano societario colegiado, cuando la imputación se dirige a los integrantes de un órgano plural no colegiado y cuando esta se justifica en la delegación de tareas.

2. En el primer caso, es decir, cuando se trata de un órgano plural colegiado, sus miembros serán solidariamente responsables por los daños que provoquen las determinaciones de este.

a) Esta decisión se justifica por la manera en que se forma la voluntad del órgano, porque sus miembros tienen una obligación de control recíproco y por cuestiones de índole práctico.

b) En materia de responsabilidad de los administradores, el factor de imputación al que debe recurrirse es subjetivo: la culpa o el dolo. Cuando la sindicación del deber resarcitorio deriva de la pertenencia a un órgano plural colegiado, esta se justifica en la denominada culpa in vigilando.

c) El principio al tenor del cual los administradores que integran un órgano colegiado son responsables por los perjuicios que produzcan las decisiones de este reconoce algunas excepciones, entre las

efectos sobre el ámbito de responsabilidad patrimonial por la conducta dañosa, que debe atender a la actividad efectivamente desarrollada, dependiendo su exención de la prueba de que el funcionario cesó en su desempeño antes de los hechos de los que resulta su responsabilidad, con prescindencia, en principio, de las registraciones respectivas. Cf. Cámara Nacional Comercial, Sala C, in re Abad, Rubén O. y otro c. Murphy, Tomás A., sentencia del 26 de junio de 1995, publicada en la Revista Jurídica Argentina La Ley, con nota de José María Curá, p. 437. 
que se destaca la que permite exonerar del deber resarcitorio a los directores que se opusieron a la decisión y formalizaron una protesta, en la forma y del modo explicado.

3. El segundo supuesto por analizar se presenta cuando el órgano plural societario no es colegiado y toma una determinación que, a la postre, resulte dañosa, en cuyo caso el deber resarcitorio no podrá sindicarse en forma solidaria a sus miembros, sino que cada administrador será individualmente responsable, de acuerdo con el grado de participación personal que tuvo en el asunto, correspondiéndole al juez fijar la parte que a cada uno corresponde en la reparación del perjuicio.

4. El tercer caso en el cual puede concretarse una imputación de responsabilidad que afecte a una pluralidad de administradores se presenta cuando se concretan delegaciones de tareas:

a) En los casos de delegación ordinaria, el sistema de responsabilidad no se modifica sustancialmente y, de producirse un hecho dañoso, responden solidariamente el administrador delegante y el delegado. Sin embargo, para evitar situaciones injustas, este principio debe aplicarse con prudencia, reconociéndose exoneraciones de responsabilidad en diferentes situaciones en las que los administradores delegantes no tuvieran participación en la gestión del manager delegado, siempre y cuando hayan agotado los recursos a su alcance para corregirlas y tomado las medidas ulteriores para enervar, reducir o reparar el daño.

b) Cuando, en cambio, se concreta una delegación por asignación específica de funciones, y se cumple con los presupuestos del artículo 274 de la Ley de Sociedades Comerciales, la imputación de responsabilidad se hará atendiendo a la actuación individual de cada uno de los administradores.

\section{Referencias}

Abdala, M. (2010). Responsabilidad de los administradores societarios. La culpa grave como factor de atribución. Revista Jurídica Argentina La Ley, 2010-B. 
Cámara Federal de Apelaciones de Bahía Blanca, Sala II, in re Ghilino, Pablo Gabriel (La Sirena S.A.) s/Apelación.

Cámara Nacional Comercial, Sala A, in re Eledar S.A. c. Serer, Jorge S/Sumario, sentencia del 8 de octubre de 1997.

Cámara Nacional Comercial, Sala A, in re Taverniti S.A. S/Quiebra S/Incidente de calificación de conducta, sentencia del 28 de abril de 1995, y Sala E, Inmobiliaria Alonso S/Incidente de calificación de conducta, sentencia del 27 de mayo de 1994.

Cámara Nacional Comercial, Sala A, in re Viajes Guinea S.A. S/Quiebra S/Incidente de calificación de conducta, sentencia del 11 de marzo de 1993.

Cámara Nacional Comercial, Sala A, in re Vid y Com. Video y Comunicaciones S.A. S/Quiebra, S/Incidente de calificación de conducta, sentencia del 10 de julio de 1992; Sala B, in re Viajes Guinea S.A. S/Quiebra S/Incidente de calificación de conducta, sentencia del 11 de marzo de 1993; in re Taverniti S.A. S/ Quiebra S/Incidente de calificación de conducta, sentencia del 28 de abril de 1995, y Sala E, Inmobiliaria Alonso S/Incidente de calificación de conducta, sentencia del 27 de mayo de 1994.

Cámara Nacional Comercial, Sala B, in re Eugenio Izak S.A. S/Quiebra, S/Incidente de calificación de conducta, sentencia del 7 de diciembre de 1994.

Cámara Nacional Comercial, Sala B, in re Marsicano, Oscar c. San Sebastián Sacif y otros, sentencia del 28 de abril de 2009.

Cámara Nacional Comercial, Sala B, in re Only Plastic S.A. S/Quiebra, S/Incidente de calificación de conducta, sentencia del 26 de marzo de 1991.

Cámara Nacional Comercial, Sala B, sentencia del 15 de marzo de 1982, publicada en El Derecho, t. 99-444.

Cámara Nacional Comercial, Sala C, in re Abad, Rubén O. y otro c. Murphy, Tomás A., sentencia del 26 de junio de 1995, publicada en la Revista Jurídica Argentina La Ley, con nota de José María Curá, t. 1995-E, Ed. La Ley, Buenos Aires, 1995.

Cámara Nacional Comercial, Sala B, in re Jinkus, Gabriel A. c. Video Producciones Internacionales S.A. y otros, sentencia del 6 de noviembre de 1996, publicada en Revista Jurídica Argentina La Ley, t. 1997-D-483, Ed. La Ley, Buenos Aires, 1997.

Gagliardo, M. (2004). Responsabilidad de los directores de sociedades anónimas. Buenos Aires: Ed. Lexis Nexis, t. I.

Kötz, H. (1996). Deliktsrecht (7ª ed.). Berlín.

Martorell, E. E., E Figueroa, F. (1994). Los directores de sociedades anónimas. Buenos Aires: Ed. Depalma.

Nissen, R. A. (2006). Lecciones de derecho societario (2a ed.). Buenos Aires: Ed. Ad-Hoc. 
Otaegui, J. C. (1979). Administración societaria. Buenos Aires: Ed. Ábaco.

Perciavalle, M. L. (2007). Acción de responsabilidad de administradores y síndicos societarios. Práctica y actualidad societaria. Buenos Aires: Ed. Errepar, t. 2.

Sasot Betes, M. A., E Sasot, M. P. (1980). Sociedades anónimas: el órgano de administración. Buenos Aires: Ed. Ábaco de R. Depalma.

Verón, A. V. (1998). Sociedades comerciales. Buenos Aires: Ed. Astrea, t. 4.

Zaldívar, E. (1983). La responsabilidad de los directores de las sociedades por acciones en la reforma de la Ley de Sociedades Comerciales año 1983. Revista Inspección General de Justicia. 